\title{
Einige Wirkungen der Amputation der optischen Tentakel bei einer Landlungenschnecke (Eobania vermiculata Müll.; Helicidae)
}

Eine hormonale Beeinflussung von Eireifung und Spermienbildung durch einen Faktor der augentragenden Tentakel wurde bei Pulmonaten mehrfach festgestellt ${ }^{1-9}$, wobei die Ergebnisse bei Nacktschnecken einheitlich, bei Heliciden dagegen z.T. widersprüchlich sind. Neben dieser Wirkung auf die Gonade führt die Exstirpation der Augententakel bei Ariolimax columbianus ausserdem zu einer Vergrösserung der Eiweissdrüse und zu vermehrter Galactogensynthese in derselben ${ }^{10}$, bei Helix aspersa zu einer Degeneration der Calciumzellen in der Mitteldarmdrüse? ${ }^{7}$. Nachfolgend werden einige Versuche geschildert, welche den Einfluss der Tentakelamputation auf das Trockengewicht der Eiweissdrüse, den Wasserverlust des ganzen Tieres während des Trockenschlafs und die Höhe des Stoffwechsels der Mitteldarmdrüse in vitro bei einer Helicide untersuchen.

Material und Methode. Den Versuchstieren (Eobania vermiculata Müller) wurden 1-3 Wochen nach der Aktivierung aus dem Winterschlaf beide Augententakel im proximalen Drittel ihrer Länge amputiert und die Tiere daraufhin drei Tage lang bei reichlichem Futter- und Wasserangebot gehalten. Anschliessend wurden sie einem mehrwöchigen Trockenschlaf $\left(21-23^{\circ} \mathrm{C}\right.$; Tageslänge 14/10) unterworfen und dabei der Gewichtsverlust regelmässig festgestellt. Danach wurde der Sauerstoffverbrauch von Mitteldarmdrüsenschnitten mittels Warburg-Apparatur bestimmt (Medium nach ${ }^{11}, \mathrm{pH}=7,5$ mit Tris-Puffer, $1 \%$ Glukose; Temperatur $20^{\circ} \mathrm{C}$ ) und das Trockengewicht der Eiweissdrüse festgestellt $\left(105^{\circ} \mathrm{C}, 8 \mathrm{~h}\right)$. Eine gleich grosse Kontrollgruppe $(N=15)$ wurde mit Ausnahme der Tentakelamputation gleich wie die Versuchsgruppe behandelt und untersucht.

Ergebnisse. Wasserverlust: Landschnecken verlieren normalerweise in den ersten Tagen des Trockenschlafs relativ viel Wasser, schränken diesen Verlust dann aber stark ein. Dieser anfängliche Wasserverlust war bei den operierten Tieren wesentlich geringer als bei den Kontrollen $(0,095$ gegenüber $0,18 \mathrm{~g} / \mathrm{Tier} / \mathrm{Tag})$; mit fortschreitender Austrocknung wurde dieser Unterschied natur-

Sauerstoffverbrauch von Hepatopankreas-Schnitten bei $20^{\circ} \mathrm{C} ; \mathrm{mm}^{3} / \mathrm{g}$ Trockengewicht/Stunde

\begin{tabular}{|c|c|c|c|}
\hline & $\begin{array}{l}\text { Tentakel- } \\
\text { operierte } \\
\text { Tiere }\end{array}$ & $\begin{array}{l}\text { Kontroll- } \\
\text { tiere }\end{array}$ & $p$ \\
\hline $\begin{array}{l}\mathrm{QO}_{2} \\
\text { Eiweissdrüse }\end{array}$ & $1100,7 \pm 270,4$ & $1406,2 \pm 325,8$ & 0,01 \\
\hline $\begin{array}{l}\text { mg Trockengew. } \\
\text { Eiweissdrüse }\end{array}$ & $43,79 \pm 35,5$ & $14,78 \pm 15,2$ & $0,02>p>0,0$ \\
\hline $\begin{array}{l}\text { Schwankungs- } \\
\text { breite in mg }\end{array}$ & $3,7-117,3$ & $3,6-61,5$ & \\
\hline$N$ & 14 & 15 & \\
\hline
\end{tabular}

Eiweissdrüsen-Trockengewicht. Mittelwerte \pm Standardabw. gemäss immer geringer, war aber noch zwischen dem 40. und 70. Tag des Trockenschlafs zwischen $5 \%$ und $2 \%$ signifikant verschieden

Eiweissdrüse. Die Tabelle gibt die Unterschiede der Trockengewichte der Versuchs- und Kontrollgruppe wieder. Tentakelamputation führt also auch bei Eobania zu einer Vergrösserung der Eiweissdrüse (und wahrscheinlich auch $\mathrm{zu}$ verstärkter Galaktogensynthese; siehe ${ }^{10}$ ). Wenn ähnliche Verhältnisse wie bei den besser untersuchten Arioniden vorliegen, müsste auch die Eireifung durch die Tentakelamputation beeinflusst werden, was Gegenstand einer laufenden Untersuchung ist.

Sauerstoffverbrauch der Mitteldarmdrüse in vitro. Die Tabelle zeigt, dass der bei $20^{\circ} \mathrm{C}$ gemessene Sauerstoffverbrauch isolierter Schnitte der Mitteldarmdrüse bei den tentakelamputierten Tieren signifikant niedriger ist als bei den Kontrollen. Die Amputation wirkte sich also nicht nur auf den Wasserverlust während des Trockenschlafs (und vermutlich auf den Gesamtmetabolismus), sondern auch auf eine in vitro fassbare Teilfunktion aus. Neben der Steuerung der Galaktogensynthese ${ }^{10}$ ist dies ein eindeutiger Nachweis einer hormonalen Stoffwechselregulation bei Gastropoden. Dass es sich nicht um eine Störung im Sinne einer allgemeinen Mangelerscheinung? handelt, zeigt die gleichzeitige Grössenzunahme und Reifung der Eiweissdrüse; es ist also sicher nicht das ganze Tier schwer geschädigt, was auch durch das lange Uberleben tentakelamputierter Tiere und die ausgezeichnet funktionierende Kontrolle des Wasserverlusts bestätigt wird.

Summary. Amputation of the optic tentacles in Eobania vermiculata causes lower water loss during aestivation, increase of dry weight of the albumen gland, and decrease of in vitro oxygen consumption of hepatopancreas tissue.

H. NOPP

II. Zoologisches Institut der Universität,

Dr.-Karl-Lueger-Ring 1, A-1010 Wien (Österreich),

18. Dezember 1970.

1 A. Guyard, C. r. Acad. Sci., Paris, Sér. D 265, 147 (1967)

2 H. Herlant-Menwis und J. J. van Mol, C. r. Acad. Sci., Paris 249,321 (1959).

3 D. Kumlmann und A. Nolte, Z. wiss, Zool. 176, 271 (1967)

4 N. J. Lane, Q. J. microsc. Sci. 103, 211 (1962). - Quart. J. microsc. Sci. 105, 35 (1964).

5 D. Pelluet und N. J. Lane, Can. J. Zool. 39, 789 (1961).

- D. Pelluet, Can. J. Zool. 42, 195 (1964).

S. SaNchez und H. Sablier, Bull. Soc. Zool. France 87, 319(1962).

8 B. J. Sмuтн, Malacologia 4, 325 (1966); 5, 285 (1967).

${ }^{8}$ G. J. Stephens und G. C. Stephens, Nature, Lond. 212, 1582 (1966).

10 V. R. Meenakshi und B. T. Scheer, Comp. Biochem. Physiol. 29, 841 (1969).

1 C. L. Prosser und F. A. Brown, (Comparative Animal Physiology; Saunders, Philadelphia, London 1961).

\section{Chromatin Differentiations in Microspores}

In studies carried out on the nuclei of meristematic cells, structures apparently related to the nucleolus have been described with a peculiar organizational density of their own, and in later studies, through enzymatic reactions, it was deduced that these structures were differentiated chromatin products and bore a relation to RNA synthesis, thus proving to be comparable with the 'puffs' of polytene chromosomes 1,2 .

Our own analysis of microsporogenesis, using Allium cepa microspores fixed in glutaraldehyde-osmium and contrasted with uranyl-lead for examination under the electron microscope, revealed certain characteristic for- 